\section{$\underset{\substack{\text { hommes } \\ \text { \& migrations }}}{ }$}

\section{Hommes \& migrations}

Revue française de référence sur les dynamiques

migratoires

$1303 \mid 2013$

Diasporas marocaines

\title{
Yves Bourron, Jamal, un migrant acteur de développement. La revanche du territoire
}

Paris, Publisud, 2011, 270 p., $16 €$.

Jacques Ould Aoudia

\section{(2) OpenEdition}

1 Journals

Édition électronique

URL : http://journals.openedition.org/hommesmigrations/2610

DOI : 10.4000/hommesmigrations. 2610

ISSN : 2262-3353

Éditeur

Musée national de l'histoire de l'immigration

Édition imprimée

Date de publication : 1 juillet 2013

Pagination : 207

ISBN : 978-2-919040-23-0

ISSN : 1142-852X

Référence électronique

Jacques Ould Aoudia, «Yves Bourron, Jamal, un migrant acteur de développement. La revanche du territoire », Hommes \& migrations [En ligne], 1303 | 2013, mis en ligne le 23 janvier 2014, consulté le 22 septembre 2020. URL : http://journals.openedition.org/hommesmigrations/2610 ; DOI : https:// doi.org/10.4000/hommesmigrations.2610

Ce document a été généré automatiquement le 22 septembre 2020.

Tous droits réservés 


\title{
Yves Bourron, Jamal, un migrant acteur de développement. La revanche du territoire
}

\author{
Paris, Publisud, 2011, 270 p., $16 €$.
}

\author{
Jacques Ould Aoudia
}

\section{RÉFÉRENCE}

Yves Bourron, Jamal, un migrant acteur de développement. La revanche du territoire, Paris, Publisud, 2011, 270 p. $16 €$.

1 Ce livre nous parle du Maroc et de la France des années 1970 à aujourd'hui. Une histoire sensible, où l'indignation face à l'injustice est intacte, du début à la fin. Une histoire pétrie des contradictions qui traversent toutes les faces de la migration.

2 Jamal est au cœur de ces contradictions. Ainsi ce qu'il nous dit des sentiments qui agitent les participants et leurs familles au moment du tri des candidats à l'émigration dans les années 1970 : qui, des déclarés aptes ou des non-aptes, sont les gagnants? les perdants? Ainsi de l'admiration pour la France qui cohabite avec celle pour son père qui a participé à la lutte pour l'indépendance. Ainsi du paradoxe de la domination coloniale et de l'émigration dans le pays anciennement colonisateur. Ainsi du passage d'une société du Sud où la loyauté soutient les rapports sociaux au travers de relations assignées, majoritairement informelles et personnalisées, à une société du Nord où c'est la légalité et la dépersonnalisation des relations qui dominent. Le migrant doit jongler avec ces deux univers et avec les faiblesses de chacun d'entre eux : la loyauté au Sud avec ses défaillances, comme la légalité au Nord.

3 La vision de Jamal pose l'individu, étroitement relié à son groupe, comme responsable de son destin. Cet individu a la possibilité de refuser la pauvreté, la soumission à l'ordre établi où les traditions soutiennent la confusion entre pouvoir et richesse. 
4 La démarche de développement participatif tire sa force de cette vision: on ne peut aider quelqu'un que s'il a la volonté de se prendre en charge, par la volonté d'apprendre, de se former. À l'individu passif qui attend que l'État lui procure emploi et équipements, Jamal oppose une claire distinction entre l'initiative individuelle dans le champ économique et la présence nécessaire de l'État dans celui des services publics. Cet État, que son action volontariste avec l'association a réussi à mobiliser en faveur du monde rural, longtemps délaissé comme appartenant au Maroc inutile. La démocratie? Jamal en a une expérience difficile dans ses relations avec les élus, mais aussi dans sa tentative cuisante de candidat aux élections. Pour lui, la démocratie se construit par le bas, en commençant au niveau du village par l'éducation sur les projets concrets de développement.

$5 \quad$ Pour ceux qui pensent que les sociétés du Sud ne sont pas des répliques défaillantes des sociétés développées mais des sociétés qui tiennent et fonctionnent avec leurs valeurs, leurs forces comme leurs facteurs de blocage, pour ceux qui pensent que le développement n'est pas la reproduction à l'identique des modes de fonctionnement et des institutions du Nord, cet ouvrage livre de précieux enseignements, élaborés sur une longue pratique, confrontés à la réalité. Jamal, passeur de modernité, passeur de développement. 